\title{
The Antarctic Circumpolar Productivity Belt
}

\author{
T. Ito \\ Joint Institute for the Study of the Atmosphere and Ocean, University of Washington, Seattle, Washington, USA \\ P. Parekh, S. Dutkiewicz, and M. J. Follows \\ Program in Atmospheres, Oceans, and Climate, Massachusetts Institute of Technology, Cambridge, Massachusetts, USA \\ Received 22 March 2004; revised 2 June 2005; accepted 8 June 2005; published 8 July 2005.
}

[1] We illustrate the mechanisms controlling the spatial patterns of biological productivity in the Southern Ocean using a coupled, physical-biogeochemical-ecological model. The model captures a belt of enhanced export production, figuratively termed as the Antarctic Circumpolar Productivity Belt. As observed, there is a maximum in silica export to the south of the peak in the organic carbon export. We show that the meridional and zonal structures of the productivity belt are strongly controlled by the residual mean circulation; the net effect of the Ekman flow and the eddy-induced circulation. The belt of maximum silica export coincides with the region of residual mean upwelling which supplies silica, iron and phosphate to the surface. The peak of organic carbon export is shifted to the north and is located at the boundary between iron and phosphate limited regimes. Here the equatorward residual mean flow supplies phosphate and aeolian deposition provides iron. Citation: Ito, T., P. Parekh, S. Dutkiewicz, and M. J. Follows (2005), The Antarctic Circumpolar Productivity Belt, Geophys. Res. Lett., 32, L13604, doi:10.1029/ 2005 GL023021.

\section{Introduction}

[2] The Southern Ocean is characterized by the high surface macro-nutrients indicating that the biological export of organic matter from the euphotic zone to the ocean interior is relatively inefficient. Martin and Fitzwater [1988] suggest that iron limits the productivity of the ecosystem so that it cannot utilize all the macro-nutrients. Subsequent iron addition experiments have indeed demonstrated that primary productivity in the region is enhanced [e.g., Boyd et al., 2000; Coale et al., 2004]. Understanding of the biogeochemistry of the Southern Ocean has been considerably advanced in recent years due to intense observational studies. The meridional distribution of sinking particulate flux across the Antarctic Circumpolar Current (ACC) has been measured using sediment traps [e.g., Wefer and Fischer, 1991; Honjo et al., 2000; Trull et al., 2001] revealing strong peaks of silica and organic carbon export. Silica export appears to peak to the south of the Polar Front and is strongly associated with seasonal diatom blooms. Moore and Abbott [2000, 2002] interpret remotely sensed ocean color data, and suggested that elevated chlorophyll concentrations are tightly coupled to the frontal structures. Estimates of regional primary productivity and export production, based on the remotely observed chlorophyll

Copyright 2005 by the American Geophysical Union. 0094-8276/05/2005GL023021\$05.00 structures, clearly indicate a strong zonal "belt" around 50S [Behrenfeld and Falkowski, 1997; Laws et al., 2000]. In an alternative approach, Schlitzer [2002] used an inverse model to evaluate export production by fitting an ocean tracer transport model to observed tracer data, and found a belt of elevated export production around $55 \mathrm{~S}$, in the vicinity of the ACC. The position of the maximum organic carbon export is close to the location of nitrate and phosphate fronts (where surface nutrient distribution has a large north-south gradient).

[3] What are the roles of large-scale ocean circulation in setting the position of the Antactic Circumpolar Productivity Belt? Although observations clearly suggest a strong coupling between enhanced export production and frontal structures in the ACC [e.g., Lutjeharms et al., 1985], the mechanisms controlling the patterns of export production are not well understood. Here we use a coupled physicalbiogeochemical-ecological model to simulate the circulation and biogeochemistry of the Southern Ocean and illustrate the physical and biogeochemical controls on the productivity belt and the relationship between physical and biological fronts.

\section{Coupled Physical-Biogeochemical Model}

[4] The physical-biogeochemical model used in this study is described in detail by Dutkiewicz et al. [2005]. The model is based on the MITgcm [Marshall et al., 1997a, $1997 b]$ configured for the global ocean at coarse resolution $(2.8 \times 2.8$ degrees, 15 vertical levels $)$ where mesoscale eddy transfers are parameterized following Gent and McWilliams [1990].

[5] Vertical transport near the base of the surface mixed layer is particularly important for the supply of nutrients to the surface layer where biological uptake occurs. The Eulerian mean flow, dominated by the wind-driven Ekman circulation, shows a relatively smooth zonal structure (Figure 1a) with upwelling to the south of the ACC and downwelling to the north. In contrast the residual mean flow, which includes the integrated, advective contribution from mesoscale eddy motions, shows a much more complex structure. Close to the Antarctic continent there are significant areas of downwelling, with a band of significant upwelling between 45 and $55 \mathrm{~S}$, though there is also significant zonal variation (Figure 1b). The balance between Eulerian mean (Ekman) and eddy advection is determined by patterns of air-sea buoyancy fluxes [Marshall, 1997] and it is this residual mean flow which dominates nutrient transport.

[6] We use a NPZD ecosystem model including two phytoplankton functional groups, one zooplankton size- 

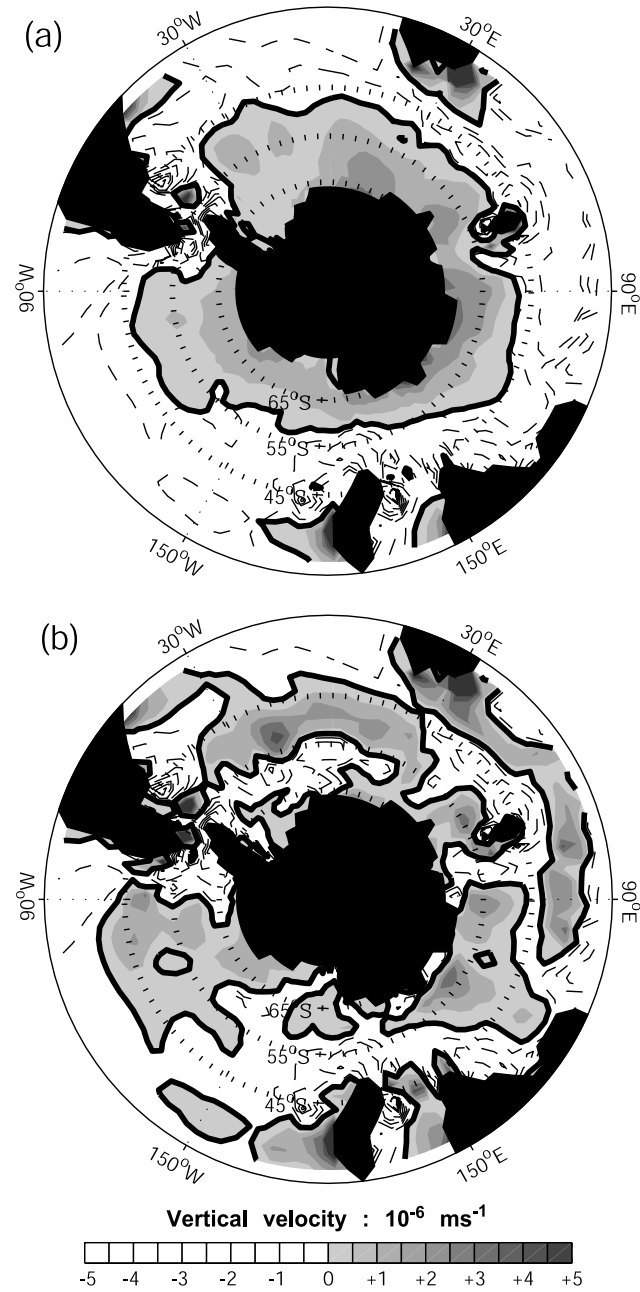

Figure 1. Vertical component of the residual mean circulation $\left(10^{-6} \mathrm{~m} \mathrm{~s}^{-1}\right)$ at 220 meters. Upwelling regions are shaded with gray scale. (a) Eulerian mean velocity mainly driven by Ekman transport. (b) Residual mean velocity, the net effect of Ekman and eddy-induced transport.

class, dissolved and particulate organic matters, and three nutrients: phosphate, silicic acid and iron. The growth rate of phytoplankton is limited by light and one of the nutrients, modeled as the minimum of Michaelis-Menton kinetics. The larger phytoplankton class, representing diatoms, utilizes silicic acid, phosphate and iron, whereas the smaller phytoplankton class, representing nano-phytoplankton, utilizes only phosphate and iron. In addition to the consumption and regeneration process common to all nutrients in the model, iron has sources and sinks due to aeolian deposition, scavenging and complexation with an organic ligand [Parekh et al., 2005].

[7] Simulated distribution of small and large phytoplankton reveals the distinct spatial patterns of the functional groups coupled to the Southern Ocean fronts. Small phytoplankton are the dominant species to the north of the ACC, where silicic acid concentrations are low relative to phosphate. To the south of the ACC, where modeled silicic acid is abundant, large phytoplankton out compete small phytoplankton similar to the previous modeling study of Aumont et al. [2003], and are perhaps too high compared to the real ocean. Figures $2 \mathrm{a}$ and $2 \mathrm{~b}$ illustrate the simulated, annual mean export production of biogenic silica and organic carbon. The simulated export is able to qualitatively reproduce the zonal belt of high biological export in the Southern Ocean.

[8] In Figure 2a, the spatial pattern of silica export is elevated in the southern flank of the ACC reflecting the distribution of large phytoplankton. Organic carbon export is driven by both small and large phytoplankton, and the belt of organic carbon export is wider in latitude and located equatorward by several degrees relative to that of silica (Figure 2b). The meridional position of the maxima in silica and organic carbon export are qualitatively consistent with the observed distributions [Honjo et al., 2000]. The magnitude of the organic carbon export has significant zonal variability from 3 to $7 \mathrm{~mol} \mathrm{C} \mathrm{m} \mathrm{Cr}^{-1}$. What controls
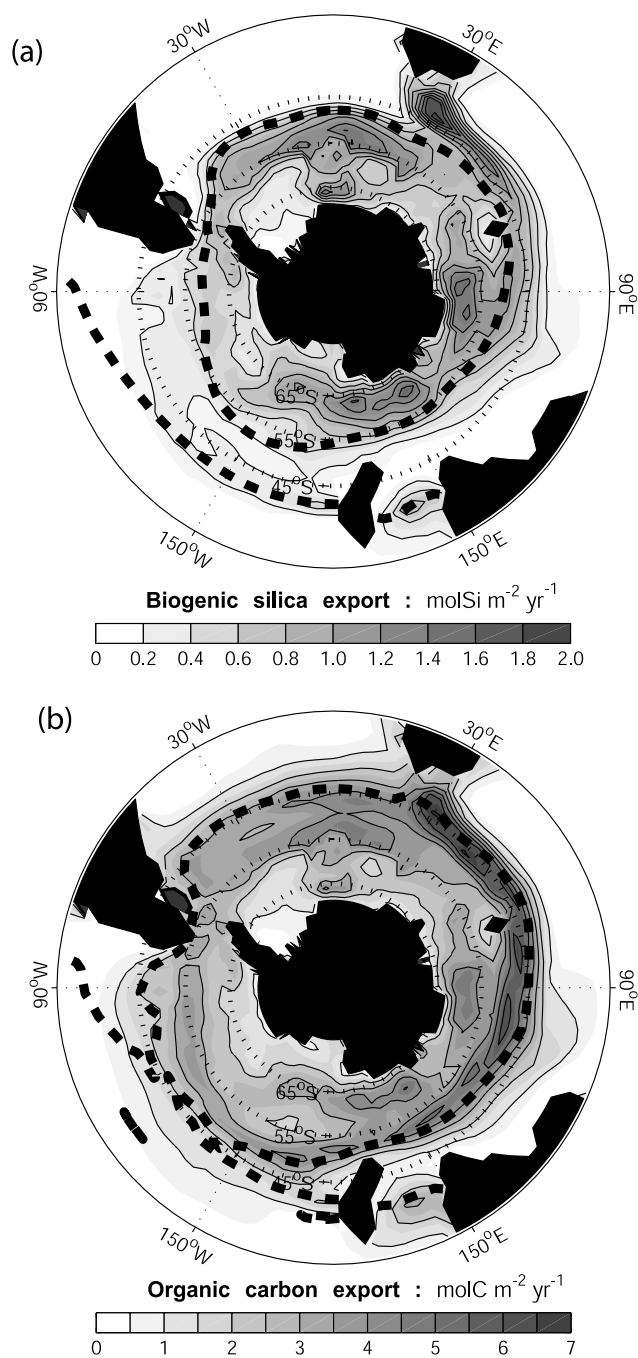

Figure 2. Modeled Southern Ocean export of sinking particles evaluated at 220m: (a) Silica export (mol Si m${ }^{-2}$ $\mathrm{y}^{-1}$ ), dashed line indicates $F e^{*}(\mathrm{Si})=0$; (b) Organic carbon export $\left(\mathrm{mol} \mathrm{C} \mathrm{m}{ }^{-2} \mathrm{y}^{-1}\right)$, dashed line indicates $F e^{*}(P O 4)=0$. In both figures $F e^{*}$ is negative to poleward of the dashed line, and positive to the north. However, in the Pacific sector, $F e^{*}$ changes sign again and is negative further north. 
Table 1. Correlation Between Residual Mean Upwelling and Export Production in the Southern Ocean (South of 50S) ${ }^{\mathrm{a}}$

\begin{tabular}{lcccc}
\hline & Atlantic & Indian & Pacific & Zonal Mean \\
\hline Corg Export & 0.57 & 0.73 & 0.42 & 0.93 \\
Silica Export & 0.16 & 0.73 & 0.15 & 0.58 \\
\hline
\end{tabular}

${ }^{a}$ These coefficients are based on spatially averaged data on a $6^{\circ} \times 12^{\circ}$ (lat-lon) grid for the Atlantic, Indian and Pacific sector of the ACC.

the pattern of simulated export production? The regional variations of both silica and organic carbon export show a close relationship with the pattern of residual mean upwelling (Figure 1b). Table 1 shows correlation coefficients between the residual mean upwelling and export production. Elevated correlation coefficients are found in the area of most vigorous export in this model, in the Indian sector of the ACC with correlation coefficients of $\sim 0.73$, where the Ekman flow alone (Figure 1a) would suggest downwelling and suppression of productivity. A significant correlation (0.93) is also found between zonally averaged organic carbon export and residual upwelling.

\section{Mechanisms Underlying the Productivity Belt}

[9] What circumstances lead to the existence of the productivity belt? What mechanisms control its position? We examine the modeled tracer distribution using a diagnostic tracer, $F e^{*}$, which indicates the decoupling between $\mathrm{Fe}$ and macro-nutrients [Parekh et al., 2005]. Fe* is defined as the difference in dissolved iron and macro-nutrient concentrations where the latter is scaled by the biological uptake ratio. Relative to phosphate, $\mathrm{Fe}^{*}\left(\mathrm{PO}_{4}\right)$ can be defined

$$
F e^{*}\left(\mathrm{PO}_{4}\right)=\mathrm{Fe}-\left\langle R_{F: P}\right\rangle \mathrm{PO}_{4}
$$

where $R_{F: P}$ represents the biological uptake ratio between Fe and $\mathrm{PO}_{4}$ which is set to $10^{-4}$ for small phytoplankton and $10^{-3}$ for diatoms within the range found by Sunda et al. [1991] and Sunda and Huntsman [1995]. The net uptake rate therefore depends upon the composition of the ecosystem, and the net uptake ratio, $\left\langle R_{F: P}\right\rangle$, is defined as the average of the uptake ratios of the two functional groups weighted by the relative abundances of small and large phytoplankton. Similarly, $\mathrm{Fe}^{*}(\mathrm{Si})$ is defined based on the relative abundance of $\mathrm{Fe}$ and $\mathrm{Si}$. In regions where $\mathrm{Fe}^{*}<0$, dissolved iron is depleted relative to the reference macronutrient and the growth of phytoplankton is limited by the availability of iron before that of the macro-nutrient. Conversely, where $F e^{*}>0$, phytoplankton growth is primarily limited by the availability of macro-nutrients. The surface distribution of modeled $F e^{*}$ indicates the regional variations in nutrient limitation regimes.

[10] The HNLC region is characterized by negative surface $\mathrm{Fe}^{*}$ (Figure 2) and the growth of organisms is limited by the availability of iron. In contrast, surface $F e^{*}$ is positive in subtropical gyres and macro-nutrients are limiting the phytoplankton growth there. In Figures 2a and $2 b$, the pattern of silica and organic carbon export is closely associated with the transition between micro and macro-nutrient limited regions marked by $\mathrm{Fe}^{*}=0$.
[11] In this model, the productivity belt and associated features are controlled in the following way (depicted schematically in Figure 3): Circumpolar deep waters, relatively rich in silicic acid and phosphate, but depleted in iron, are brought to the surface in the southern flank of the ACC by the residual mean flow. Since dust deposition is very low in this region, vertical supply of Fe by residual mean flow ultimately controls the primary and export production. In the spring and summer months, when light limitation is relieved, diatoms thrive in the upwelling regions and dominate the modeled ecosystem, stripping out silicic acid and exporting them vertically to the deep ocean. Unutilized surface phosphate are transported northwards following the residual mean flow. On the northern flank of the ACC, silicic acid is strongly drawn down relative to phosphate leading to the Si limitation of diatoms consistent with the observation [e.g., Smith et al., 2000], and the ecological community of the model shifts to favor small phytoplankton. A strong export production continues as far north as $45 \mathrm{~S}$, mainly driven by small phytoplankton. Aeolian iron supply increases northwards, and phosphate is drawn down north of $40 \mathrm{~S}$ (See $\mathrm{Fe}^{*}\left(\mathrm{PO}_{4}\right)=0$ contour (Figure 2b), thus the organisms are primarily limited by macro-nutrients there.

[12] The residual mean circulation must be consistent with air-sea buoyancy fluxes [Marshall, 1997] leading to upwelling generally to the south of the coarsely resolved ACC in this model. The regions of residual mean upwelling provide a strong source of nutrients (silica, iron and phosphorus) to the surface ocean, driving vigorous local primary production, especially of the large, silica dependent phytoplankton. Hence the belt of silica export mirrors closely the pattern of residual mean upwelling (but not Ekman upwelling) and occurs to the south of the ACC. Iron limitation prevents the complete drawdown of phosphorus in the regions of residual mean upwelling (with negative $\mathrm{Fe}^{*}$ ). The region of strongest organic carbon export occurs to the northwards of the model's ACC and the region of upwelling. It is supported by the transfer of excess phosphate by the northwards surface residual mean flow and the enhanced aeolian iron supply which increases to the north. The position of the $\mathrm{Fe}^{*}\left(\mathrm{PO}_{4}\right)=0$ contour marks position of optimal nutrient availability for small phytoplankton and hence the belt of strongest production. The position of this



Figure 3. Schematic depiction of the mechanisms controlling the position of the regime transition for limiting nutrients and the position of the productivity belt. Arrows in the box depict the residual mean circulation. 
belt, to the north of the ACC, is dictated by the balance of lateral phosphate supply from the south and iron supply from the atmosphere.

\section{Conclusion}

[13] We have illustrated the mechanisms controlling export production in the Southern Ocean using a coupled physical-biogeochemical model including an ecosystem of intermediate-complexity. The model reproduces a circumpolar belt of high export production figuratively termed as the "Antarctic Circumpolar Productivity Belt" which is qualitatively consistent with observed estimates of Wefer and Fischer [1991], Honjo et al. [2000], and Trull et al. [2001] and inverse modeling of Schlitzer [2002]. The broad maximum of organic carbon export spans the frontal region with contributions from diatoms and small phytoplankton. The simulated peak in organic carbon export is located near the regime transition between the iron-limited Antarctic zone and macro-nutrient limited Subantarctic zone where organisms have optimal access to both nutrients as indicated by the diagnostic tracer, $F e^{*}$.

[14] The major emphasis in this paper has been on understanding the zonal "belt" structure of export production related to the north-south contrast of tracer distribution. There is significant zonal variability [Moore and Abbott, 2000] in the observed productivity at the latitudes of the ACC. In the model, the pattern of residual mean upwelling plays a key role in controlling the zonal variability of primary and export production. The pattern of residual mean upwelling is, in turn, strongly coupled to the patterns of surface buoyancy flux, wind stress and orographic features. The relative influences of these physical controls and the resulting zonal variations in upwelling and productivity is yet to be clarified.

[15] What might be the response of the Antarctic Circumpolar Productivity Belt to the changes in the physical circulation and atmospheric dust deposition of iron in the region? Sensitivity studies with numerical models have also been used to speculate about changes in productivity associated with climate variability [e.g., Bopp et al., 2003]. We believe that the conceptual framework developed here, which intimately connects the productivity regimes of the Southern Ocean to its circulation and external iron supply, can provide a useful tool for interpreting such similar simulations and connecting the biogeochemical, paleorecords to our understanding of the circulation of the ocean and climate.

[16] Acknowledgments. We thank two anonymous reviewers for their comments. We are grateful for the support from PARADIGM NOPP (N000014-02-1-0370). MJF is also grateful for support from NSF grant OCE-0136609. TI is grateful for the support from the Office of Polar Program at NSF and JISAO postdoctral fellowship. This publication is partially funded by the Joint Institute for the Study of the Atmosphere and Ocean (JISAO) under NOAA Cooperative Agreement NA17RJ1232, contribution 1139.

\section{References}

Aumont, O., E. Maier-Reimer, S. Blain, and P. Monfray (2003), An ecosystem model of the global ocean including $\mathrm{Fe}, \mathrm{Si}, \mathrm{P}$ colimitations, Global Biogeochem. Cycles, 17(2), 1060, doi:10.1029/2001GB001745.

Behrenfeld, M., and P. Falkowski (1997), Photosynthetic rates derived from satellite-based chlorophyll concentration, Limnol. Oceanogr., 42, 1-20.

Bopp, L., K. Kohfeld, and C. L. Quéré (2003), Dust impact on marine biota and atmospheric $\mathrm{CO}_{2}$, Paleoceanography, 18(2), 1046, doi:10.1029/ 2002PA000810

Boyd, P., et al. (2000), A mesoscale phytoplankton bloom in the polar Southern Ocean stimulated by iron fertilization, Nature, 407, 695-702.

Coale, K., et al. (2004), Southern Ocean iron enrichment experiment: Carbon cycling in high- and low-Si waters, Science, 304, 408-414.

Dutkiewicz, S., M. Follows, and P. Parekh (2005), Interactions of the iron and phosphorus cycles: A three-dimensional model study, Global Biogeochem. Cycles, 19(X), GB1021, doi:10.1029/2004GB002342.

Gent, P. R., and J. C. McWilliams (1990), Isopycnal mixing in ocean circulation models, J. Phys. Oceanogr., 20, 150-155.

Honjo, S., R. Francois, S. Manganinia, J. Dymond, and R. Collier (2000), Particle fluxes to the interior of the Southern Ocean in the Western Pacific sector along $170^{\circ} \mathrm{W}$, Deep Sea Res. Part II, 47(15), 3521-3548.

Laws, E., P. Falkowski, W. Smith, H. Ducklow, and J. McCarthy (2000), Temperature effects on export production in the open ocean, Global Biogeochem. Cycles, 14, 1231-1246.

Lutjeharms, J., N. Walters, and B. Allanson (1985), Oceanic frontal systems and biological enhancement, in Antarctic Nutrient Cycles and Food Webs, edited by W. Siegfried, P. Condy, and R. Laws, pp. 11-19, Springer, New York.

Marshall, D. (1997), Subduction of water masses in an eddying ocean, J. Mar. Res., 55, 201-222.

Marshall, J., A. Adcroft, C. Hill, L. Perelman, and C. Heisey (1997a), A finite-volume, incompressible Navier Stokes model for studies of the ocean on parallel computers, J. Geophys. Res., 102(C3), 5753-5766.

Marshall, J., C. Hill, L. Perelman, and A. Adcroft (1997b), Hydrostatic, quasi-hydrostatic, and nonhydrostatic ocean modeling, J. Geophys. Res., $102(\mathrm{C} 3), 5733-5752$.

Martin, J., and S. Fitzwater (1988), Iron deficiency limits phytoplankton growth in the north-east pacific subarctic, Nature, 331, 341-343.

Moore, J. K., and M. R. Abbott (2000), Phytoplankton chlorophyll distributions and primary production in the Southern Ocean, J. Geophys. Res., 105(C12), 28,709-28,722.

Moore, J. K., and M. R. Abbott (2002), Surface chlorophyll concentrations in relation to the antarctic polar front: Seasonal and spatial patterns from satellite observations, J. Mar. Syst., 37, 69-86.

Parekh, P., M. Follows, and E. Boyle (2005), Decoupling of phosphorus and iron in the global ocean, Global Biogeochem. Cycles, 19, GB2020, doi:10.1029/2004GB002280.

Schlitzer, R. (2002), Carbon export fluxes in the Southern Ocean: Results from inverse modeling and comparison with satellite based estimates, Deep Sea Res. Part II, 49, 1623-1644.

Smith, W. O. J., R. F. Anderson, K. Moore, L. A. Codispotid, and J. M. Morrisone (2000), The US Southern Ocean Joint Global Ocean Flux Study: An introduction to AESOPS, Deep Sea Res. Part II, 47(15), 3073-3093.

Sunda, W., and S. Huntsman (1995), Iron uptake and growth limitation in oceanic and coastal phytoplankton, Mar. Chem., 50, 189-206.

Sunda, W., D. Swift, and S. Huntsman (1991), Low iron requirement for growth in oceanic phytoplankton, Nature, 351, 55-57.

Trull, T. W., S. G. Bray, S. J. Manganini, S. Honjo, and R. Francois (2001), Moored sediment trap measurements of carbon export in the subantarctic and polar frontal zones of the southern ocean, south of Australia, J. Geophys. Res., 106(C12), 31,489.

Wefer, G., and G. Fischer, (1991) Annual primary production and export flux in the southern-ocean from sediment trap data, Mar. Chem., 35, $597-613$.

S. Dutkiewicz, M. J. Follows, and P. Parekh, Program in Atmospheres, Oceans, and Climate, Massachusetts Institute of Technology, Cambridge, MA 02139, USA.

T. Ito, Joint Institute for the Study of the Atmosphere and Ocean, University of Washington, Box 354235, Seattle, WA 98195-4235, USA. (ito@atmos.washington.edu) 